\title{
The Time is Now: The Need for an Intensive, Appropriate Individual Intervention for Individuals with Rett Syndrome
}

\begin{abstract}
Keywords: Rett syndrome (RTT); Medical ethics; Intervention programs

\section{Abstract}

Rett syndrome (RTT) is a complex neurological disorder caused by an affected MECP-2 gene, primarily affecting females. In 2007, a reversal of typical clinical characteristics of MECP2 mice was performed successfully. The results suggest that similar reversals might be achieved in human patients with RTT in a foreseeable future. Nonetheless, this future cure will not be able to reverse already acquired disabilities and limitations, such as osteoporosis, muscle degeneration, orthopedic contractures, and functional loss attributed to a long sedentary life typical for this group of clients. Evidence suggests that many aspects of clients' well-being and functional status depend on the therapeutic interventions they receive. Findings from diverse, intensive therapeutic programs implemented both with mice and individuals with RTT imply that such programs can enhance longevity, communications, learning, well-being, functional ability, and other life aspects characterizing this syndrome.
\end{abstract}

The authors therefore urge that individuals with this syndrome should be treated with an intensive intervention programs from childhood to maintain their optimal functional performance and medical condition so that maximal gains will be achievable for those individuals with the availability of the forthcoming genetic cure.

\section{Introduction}

Rett syndrome (RTT), a neurological disorder found mainly in females is characterized by normal birth and apparently normal psychomotor development during the first 6-18 months of life $[1,2]$. The child then enters a short period of developmental stagnation, followed by rapid regression in language and motor skills. The trademark of the disease is the repetitive stereotypical hand movements appearing when the child enters stage II of RTT. Additional characteristics of Stage II of the disorder include autisticlike behavior, panic-like attacks, bruxism, breathing irregularities, episodic apnea and/or hyperpnea, gait ataxia and apraxia, and tremors [3]. After this period of rapid deterioration, despite the relatively stable state of the disease the child with RTT might develop dystonia and if not ambulant, might also develop foot and hand deformities [4]. Seizures occur in $60-80 \%$ of individuals with RTT [3], some showing early onset epileptic variant with neonatal seizures $[5,6]$. Females with RTT typically survive into adulthood indicating a need for long-term care of these women [7].

The severity and duration of the difficulties presented by the individual with RTT call for individual adaptation of interventions in all educational and therapeutic areas. Research shows that brain development continues after the onset of RTT and that cognitive and communicative abilities of the individual with RTT do not

\section{Journal of} Syndromes

Rachel Nissanholtz-Gannot ${ }^{1,2}$, Avi Zigdon ${ }^{1 *}$ and Meir Lotan ${ }^{3,4}$

${ }^{\prime}$ Department of Health System Management, Ariel University, Ariel, Israel

${ }^{2}$ Mayers-JDC-Brookdale Institute, Jerusalem, Israel

${ }^{3}$ Israeli Rett Syndrome Evaluation Team, Chaim Sheba Medical Center, Tel Hashomer, Israel

${ }^{4}$ Department of Physical Therapy, Ariel University, Ariel, Israel

\section{*Address for Correspondence}

Avi Zigdon, Ph.D. Department of Health System Management, Ariel University, Ariel 40700, Israel, Tel: 972506010055; E-mail: zigdona@gmail.com

Submission: 15 September 2015

Accepted: 29 October 2015

Published: 04 November 2015

Copyright: () 2015 Zigdon A, et al. This is an open access article distributed under the Creative Commons Attribution License, which permits unrestricted use, distribution, and reproduction in any medium, provided the original work is properly cited.

deteriorate over time [8]. Therefore, it is vital to set proper and achievable therapeutic educational and communicational goals for the individual with RTT $[2,9]$.

Common sense suggests that overcoming all the above-mentioned impediments requires therapeutic interventions throughout the life of the person with RTT. Disturbing findings, however, suggest a drop in the use of health services, mostly in adulthood, concurrently with the apparent clinical deterioration in this population [10].

Findings from Professor Bird's laboratory in 2007 [11], which were later replicated by others $[12,13]$, suggest that by implementing a genetic manipulation, many of the clinical symptoms typical to adult mice with the MECP2 mutation can be reversed [14].

The significance of this finding is that if it becomes possible to implement a similar manipulation in human subjects carrying the defective MECP-2 gene, all individuals, including adults diagnosed with RTT, will show a significant improvement throughout their clinical manifestation. The race for the cure that began in 2007 is in full motion today [14], yet it is not expected to bear implementable fruits within a foreseeable future [15].

Despite some optimistic premise that such a cure, when achieved, will bring, there are three major difficulties:

The level of genetic engineering necessary for developing such a cure is still non-existent, and is expected to be available in the future [15].

Individuals with RTT not receiving an appropriate intensive intervention might regress [15], whereas a more intensive approach might preserve and even improve their overall abilities $[2,16]$.

The future cure will reverse the defect in the MECP-2 gene and help persons on the neuronal level, where brain developmental arrest has been observed, yet it will not reverse the limitations and handicaps that have developed since the outbreak of the disorder, (such as muscle wasting and muscle shortening, osteoporosis, 
joints contracture, hands, feet and spinal deformities, deteriorated functional abilities, and poor cardio-respiratory function), caused by the sedentary life style typical for this group of clients.

This optimistic yet problematic situation requires the implementation of appropriate, comprehensive, individually tailored, intensive intervention programs that enhance the overall functional and medical state of this group of clients. The array of neurological and orthopedic difficulties that characterize individuals with RTT requires an appropriate individualized therapeutic intervention program for the duration of the individual's life to prevent them from further deterioration. Due to the rarity of RTT and variability of individual involvement, multiple intervention programs should be implemented across multiple and varied treatment sites using long distance telehealth intervention such a program have been implemented in Ireland with 5 families receiving skype supervision using PAR (Participatory Action Research) approach, with impressive improvements (one girl started walking un aided at age 18, one girl started running and hopping at age 6 etc.) for all participants [17].

The present article demonstrates that intensive therapeutic interventions implemented in the past have yielded positive results for this group of clients [2]. It is suggested that such intensive programs should be the norm for this population until the genetic technology allowing the clinical use of the anticipated cure is at hand.

\section{Intensive Intervention for Mice with RTT}

Kondo of Australia has shown that environmental enrichment for genetically engineered mice with RTT improves functional cognitive and motor abilities [12]. The improvement in mice exposed to environmental enrichment was associated with elevated levels of cerebellar brain-derived neurotrophic factor (BDNF), in comparison with a control group that received no intervention and showed reduced level of the substance. In a different approach, other positive findings were also reported by others [13].

Such projects might yield similar results in individuals with RTT and are highly recommended. Therefore, the next section of the article reviews the results of intensive intervention programs (i.e. an enriched environment) applied over the years with this group of clients.

\section{Learning Abilities}

It is extremely difficult to evaluate the cognitive abilities of individuals with RTT as these are masked by their motor, apractic and atactic difficulties, which limit normative evaluation. On the other hand, many research projects have suggested that individuals with RTT are able to learn [18-21], and that the learning skills can be enhanced with appropriate motivational factors [18] as well as that learning is sustained after a 'washout' period of the learning program has ended [18]. It is also clear today that individuals with RTT can learn new skills $[22,23]$, including literacy $[20,21,24]$, and that learning ability is sustained in individuals with RTT at all ages $[22,25,26]$.

\section{Communication Abilities}

Individuals with RTT have emotional, social and communicative needs, yet these needs are coated by an envelope of complex disabilities, in a way which makes it extremely difficult for others to identify and correctly interpret their communication signals [27]. Yet, when the motivation of the person with RTT is high enough and the people caring to her needs are attentive enough, she will be able to convey her needs and wants and drastically improve her wellbeing $[19,28,29]$. Today we know that individuals with RTT are able to communicate once given the appropriate tools [30] such as body signals, voices, picture symbols, communication boards, or different gestures $[19,25]$. An intensive communication program which was implemented by the domestic environment and was supported by the educational facility has led to significant improvement in communication abilities in 3 girls with RTT over a two years period [16].

\section{Manual Abilities}

The vast majority of individuals with RTT display poor manual abilities that stem according to researchers from a combination of apraxia, lack of experience and deliberate avoidance of functional tasks that the child perceives as ones that will end in failure [23]. When measuring manual abilities within the conventional therapeutic intervention suggested today to individuals with RTT, a long and constant decline in functional handedness is observed [31]. On the other hand Sullivan, Laverick \& Lewis described a case study of a child with RTT who participated in a program designed to enhance her control over switch activated toys for the duration of one year [32]. At the end of that year she showed control and independence in activating different switches in the classroom. Similar results are also described by Pizzamiglio et al. describing the return of manual abilities to a child with RTT as a result of an intensive cognitive-rehabilitativesensory intervention program, which was implemented both at home and at the educational center, over the duration of 3 years [33]. In an intensive intervention program that was implemented with three children with RTT, the participants gained hand function by using a touch screen on the computer [34]. Intensive hippotherapy programs that were implemented at least three times per week was found to minimize hand stereotypes and improve intentional hand function in three individuals with RTT [35].

These findings support the testimonies that the conventional intervention programs suggested to this group of clients are insufficient to achieve manual improvement while enough evidence supports the notion that intense appropriate intervention programs can improve manual abilities in this group of clients [32].

\section{Functional Ability}

Despite the functional disabilities typical of many with RTT, half an hour daily treadmill program, which was implemented for the duration of two months, with four children with this condition, yielded significant functional improvements. These improvements included the ability to ascend and descend stairs, the speed of walking, the ability to knee walk, and more [36]. Three children with RTT were integrated in a two years intervention period within the Conductive Education (CE) program. The CE flags independence and involvement of the students in daily situations and later as participants in society. This program is also known as more demanding and more intensive 
than conventional educational programs. The participants in the above mentioned study showed improvements in functional abilities when measured with the Australian Rett scale [16]. In contrast, to those findings a stable slightly deteriorating trend was observed in children with RTT which were treated within conventional programs [37]. Others current evidence show that the balance and the ability to surmount obstacles during independent gait can be improved through intensive hippotherapy programs when implemented at least three times a week with individuals with RTT [35].

The literature describes three separate case studies of adults with RTT who had lost walking abilities and have been sitting in a wheelchair for 5 years, 15 years and over 20 years [23,38,39]. All have regained walking abilities as a result of intensive intervention programs.

\section{Orthopedic Problems}

Intensive physical therapy program as a solution to orthopedic problems in individuals with RTT has over the years unanimously been recommended by all experts in field [40-43]. Intensive intervention has been shown to reverse the progression of scoliosis in one child with RTT [44], and has prevented the need for surgery in others [45]. While McClure and associates urge that physical and hydrotherapy are proper modes of intervention and can reduce orthopedic problems in this group of clients, others present evidence that scoliosis can be reversed; functional muscle tone can be enhanced; and posture can be improved through intensive hippo therapy programs implemented at least three times a week $[35,40]$.

\section{Sensory Problems}

Many with RTT receive unclear; disorienting sensory input especially through the proprioceptive system [46]. It seems that an appropriate proprioceptive input regime, which will be implemented from a young age, can lead to reduction in fear of movement, and an enhanced desire to ambulate in this group of clients [2]. In a single case study an intensive sensory diet was implemented over a few months both at home and at the educational facility of the child. The study found a significant reduction in reaction time and in hand mannerisms, an improvement in concentration within educational situations, elongation of time of involvement in tasks, and improvement of eye contact [47].

\section{Digestive Problems}

Feeding difficulties and digestive disturbances are common in patients with RTT [48]. They may compromise weight and growth, often leading to malnutrition [49]. In a recently published article the authors performed gastrointestinal and nutritional assessment based on a previously designed protocol in 25 participants with RTT. Intervention was performed individually with 7 patients and resulted in improvements in BMI and reduced severity of constipation and gastroesophageal reflux symptoms. Previous findings suggest that implementing good nutritional management can improve not only the weight of the individual with RTT, but also her activity level and her functional abilities $[49,50]$. The present and previous findings supports yet again the assumption that an early intervention program, individually planned and executed can improve the quality of life of individuals with RTT [51]. The need for an intensive, appropriate, carefully planned nutritional support is not new, and has been also raised by others $[48,50,52]$.

Despite such accumulating evidence, due to rarity and individual phenotypic expression of individuals with RTT the strength of the majority of the literature described above is graded (according to the American Academy for Cerebral Palsy and Developmental Medicine (AACPDM) level of evidence rating scale in which Level I represents the highest level of evidence and grade $\mathrm{V}$ as lowest scientific evidence) as scientific rigour at grades IV-V [53].

\section{Ethical Issues}

With respect to the data presented above, we argue that patients with RTT must be given access to intensive up-to-date medical and physical care, in order to improve and/or preserve their condition as much as possible until a remedy to their condition becomes available.

Our social duty to provide treatment for patients with RTT stems from several moral principles. We chose to refer to four principles:

$$
\begin{array}{ll}
* & \text { Dignity } \\
* & \text { Equality } \\
* & \text { Improvement } \\
* & \text { Cost-benefit considerations }
\end{array}
$$

It is important to note that these principles are not in the same level of consideration. Dignity and Equality are considered as fundamental rights and, for example, have specific reference at the European Charter of Fundamental Rights (Charter of Fundamental Rights of The European Union, 2001/2009), Improvement (of the physical condition) and Cost-benefit considerations are important considerations, however, they are not as high at the hierarchy as Dignity and Equality (Swedish Parliamentary Priorities Commission).

\section{Dignity}

Human dignity is a supreme intrinsic value. All people are born equal and none are more equal than others. People who are handicapped, ill, physically disabled or mentally deficient due to illness or injury are also human beings, and no one can deny them their right to dignity [54]

Respect for mankind and the value of dignity have been the topics of an extensive body of literature, written particularly during the period following the Second World War [55]. These values have also been addressed in various documents that deal with human rights. In the United States, the value of dignity is associated with individual rights, including the freedom of individuals to act without government intervention [56].

The concept of dignity was summarized by Thurgood Marshall (an Associate Justice of the United States Supreme Court) as follows: "In recognizing the humanity of our fellow beings, we pay ourselves the highest tribute" [57]. His statement implies that dignity, rather than economic calculations, should be the major consideration in implementing therapeutic interventions to minority groups such as individuals with RTT.

In most democratic countries one of the practical expressions 
of this supreme right is the provision of accessible health services, particularly for people who are incapable of independently caring for their own needs. We consider access to health services as part of the natural right to dignity for individuals with RTT. Providing patients with RTT with intensive medical treatment is a practical expression of respect for humanity, since access to treatment allows RTT patients to preserve their abilities [16-52]. Providing care also contributes to the effectiveness of future treatments designed to improve their function. By receiving intensive treatment, patients with RTT will have the opportunity to improve their condition or at least not lose further abilities and, with the future cure, regain the respect as equal members of society that they lost with the onset of the symptoms of RTT.

\section{Equality}

Equality is a fundamental value in all civilized nations. The principle of equality is of utmost importance since it serves as the foundation for democratic rights and the basis for the values of democracy. Legal systems throughout the world view equality as the supreme legal norm [58].

The value of equality has numerous implications and encompasses many legal rights, such as: equality before the law (legal equality), equality of welfare and equality of resources.

Health is not egalitarian by nature, since many people are born with conditions that prevent them from being healthy. Patients with RTT cannot enjoy good health, and therefore we are morally obligated to take action within the framework of healthcare, educational, and other systems to guarantee the best possible lives for individuals with RTT. Preserving physical abilities is one of these obligations. The healthcare system is obligated by the value of equality to help create a more egalitarian society (giving more support to individuals who need more); such action, however, requires a commitment of stakeholders at all levels, from policy makers to healthcare providers [59].

If a remedy that could enable RTT patients to lead normal or nearly normal lives were available, we would be obligated to preserve their condition until they receive the remedy, and give them the opportunity to enhance their lives to a point at which they could lead normal or near-normal lives, or at least drastically improve their lives and condition. There is currently no remedy for RTT, but there are significant indications that a remedy may be available within the foreseeable future. Society is therefore obligated today, in anticipation of that future remedy, to take the utmost available measures to preserve/improve the condition of RTT patients. Failure to do so at the present time will directly impair their future right to become equal, healthy members of society after they receive treatment, and will undermine their equal opportunity for a better life, which every person deserves.

\section{Improvement}

Improvement is a significant principle in medical ethics and the aim of the Therapist/caregiver is always to improve the patient's condition, even if the patient cannot be fully cured [60].

Improvement has several aspects. The overall aspect is to bring about an end to the illness and to return the patient to a normal life, subject to the medical context and the patient's unique circumstances. Obviously this objective cannot always be attained, and we therefore tend to assess medical treatment by evaluating the expected degree of improvement in the patient's condition.

Research shows that compliance with a regular regime of physical activity to prevent disease and maintain health is important in all client populations [61]. The question is how much money such programs cost and is that money worth spending to improve the quality of life?

When drawing up regulations, government agencies place value on human life and then weigh the costs versus the lifesaving or benefits of a proposed rule. This calculation is called "statistical life". According to the US Environmental Protection Agency, the value of human life is calculated as 6.9 million United States Dollar (USD) [61]. "Quality-Adjusted Life-Year (QALY)", which is the value of statistical life divided by human life expectancy, is calculated today between 75,000 USD (suggested by the American administration) [40] and 50,000 USD (calculated by the medical insurance industry) [62]. Others argue for much higher sums as conceivable measures to determine "worthwhile medical interventions" [62]. Today, the average annual cost of medical management per person with RTT in Australia is 21,158 USD [10]. Therefore, much more can be invested in care for this population per person, annually and still be considered "worthwhile medical interventions."

Intensive therapeutic treatment for clients with RTT are brings about immediate improvement in their ability to function in many areas such as motor abilities, communication, and manual function [16-52]. In addition, such treatments also enhance their chances for improvement and living a fuller life in the future. Without the intensive treatment recommended in this article, their current condition is expected to gradually deteriorate and they will lose the possibility of benefiting from the cure for RTT, when it becomes available [37]. On the other hand, if they receive the proposed intensive treatment, their current physical condition will be preserved and possibly improved, and their chances for significant recovery in the future will be extremely high. For this reason, the obligation of readers of the present article and of medical policy makers is to offer them the best possible chances for improvement both now and in the future.

\section{Cost-benefit analysis}

The principle of cost-benefit analysis states that treatment should be administered taking into consideration both its cost and its corresponding benefit. In the past, cost was merely a secondary factor in healthcare decisions regarding whether or not to administer treatment [63]. Today, in a world of limited resources, this principle is widely used, and policy makers assess the feasibility of medication or medical technology according to the principle of cost-benefit [64]. The theory behind this principle is that to be feasible, medical treatment must improve health. In a world of limited resources, it is advisable to invest in one channel or another. This is one of the outstanding guiding principles in weighing whether or not to administer specific medical treatments [65]. Applying this principle to treatments for patients with RTT reveals that intensive rehabilitative treatment is more cost-beneficial than maintenance-level interventions and 
therefore should be provided to this population.

The literature suggests that at the present state and with the current level of health-related care, this population shows a slight tendency to deteriorate gradually over the years [35]. The treatments necessary to improve the condition of clients with RTT are mainly motoric therapies (such as physiotherapy, hydrotherapy, and hypotherapy) as well as diet and sensory therapies (such as nutrition, occupational therapy and more), rather than pharmaceutical treatment. The cost of health-related treatments depends on the setting; In Israel, the cost of such treatments reaches 100 USD per session. As shown by the literature presented earlier, failure to treat this group of clients significantly diminishes, or even eliminates the effectiveness of a future remedy. Below, using several examples of interventions typically used to treat individuals with RTT (a wheelchair, a scoliosis operation, and a specially adapted car), we compare the lifetime costs of such treatments and replacement of such accessories (suggested for a disabled person) with the cost of direct therapy sessions that provide an "enriched environment", ultimately improving the child condition and saving money.

Therapeutic management aimed at achieving mobility - The current cost of a specially adapted wheelchair is approximately 1,250 USD or even more. Girls with RTT who are not mobile are prone to develop curvature of the spine or other deformities and require a wheelchair with an insert, which must be replaced every few years [2]. If we calculate replacement once every five years, the cost of a wheelchair for a single girl with RTT over a period of 50 years, from childhood to adulthood, the lifespan of a patient with RTT $[7,15]$ is 12,250 USD, a sum equal to the cost of 122 health-related treatments for individuals with RTT.

A second example to illustrate the ability of intensive intervention aimed at mobility independence to reduce future costs of support for individuals with RTT could be presented when acknowledging the fact that an intensive treadmill intervention can improve function as well as mobility of children with RTT [36]. Preserving each girl's independence and mobility will save the National Insurance Institute between 50,000 to 75,000 USD, which is the cost of one specially adapted vehicle. Such vehicles need to be replaced every five or six years, which implies that by eliminating the need for one vehicle per client over her lifespan (750,000 USD); we can release sums that cover 7,500 health-related treatments.

Therapeutic management aimed at reduction of spinal deformities - Intensive physical therapy intervention has been found to reverse curvature or maintain spine alignment in individuals with RTT [2], thereby eliminating the need for future corrective spinal surgery [2], which costs approximately 120,000 USD [66] (post-op rehabilitation and recuperation included). This example presents that maintaining spine alignment for one individual with RTT will save the healthcare system the equivalent of 1,200 health-related treatments.

Consequently, it seems that an intensive program for individuals with RTT is more cost-effective in the long run than the present therapeutic management scarcely implemented with this group of clients.

Moreover, Tilford and associates illustrated the use of costeffectiveness analysis to assess interventions for improving outcomes in children by calculating the cost per quality-adjusted life year (QALY) gained from technological changes in treatment [66]. Cost and survival data were associated with technological change in the treatment of children with a disorder/disease (in their case, children with traumatic brain injury - TBI). The researchers report that sensitivity analysis indicated that if survivors live more than five years, then the estimated cost-effectiveness ratio seems favorable. In research interventions performed with mice with RTT to date, interventions with new medications/techniques were found to support longevity in the evaluated RTT mice [10]. Therefore, this group of client whose life expectancy was assessed in the past at 50 years can be promising candidates for an intensive/enhanced health related interventions [7].

\section{Conclusions}

Since the reversal of clinical RTT symptoms in mice in 2007 at Adrian Bird's laboratory, it is merely a question of time until a similar genetic change will be possible in human beings with this disorder [15]. Nonetheless, current conventional treatment programs for this group of clients, offer a low-level therapeutic intensity, which gradually leads to decline into extreme levels of sedentary life style, wasted muscles, loss of ambulation abilities, reduction in cardiorespiratory function, while on the other hand augment osteoporosis, muscle shortening, reduction in joint's range of motion and the development of contractures, and more. Such losses will not be retrievable when the future genetic cure is available.

There is, however, a growing body of knowledge that indicates that regression in the condition of individuals with RTT is not inevitable $[67,68]$ and may be halted by appropriate interventional programs [17]. Evidence shows that when sufficiently intensive programs were accompanied by appealing motivational factors, individuals with RTT were able to achieve impressive improvements in function, manual abilities, spinal deformation, posture, communication, sensory input, as well as educational and motor abilities [16-52].

A growing body of research suggests that intensive, sustained treatment is important in exerting positive rehabilitative effects in many developmental conditions [69], such as RTT. Furthermore, the evidence emphasizes the importance of an overall developmental framework, and the emergence of guiding principles for program design and development.

Moreover, the present article has offered strong ethical as well as financial considerations that support an immediate intensification of current health management programs for this group of clients. If such action is not taken in time, we will have played a role in limiting the potential benefit of future treatments for individuals with RTT, who will consequently be forever trapped within their disabled bodies.

\section{References}

1. Amir RE, Van den Veyver IB, Schultz R, Malicki DM, Tran CQ, et al. (2000) Influence of mutation type and $X$ chromosome inactivation on Rett syndrome phenotypes. Ann Neurol 47: 670-679.

2. Lotan M, Merrick J (eds) (2011) Rett syndrome: therapeutic interventions. Disability studies series, Nova Science Publishers, New York.

3. Krajnc N (2015) Management of epilepsy in patients with Rett syndrome: perspectives and considerations. Ther Clin Risk Manag 11: 925-932. 
Citation: Nissanholtz-Gannot R, Zigdon A, Lotan M. The Time is Now: The Need for an Intensive, Appropriate Individual Intervention for Individuals with Rett Syndrome. J Syndromes. 2015;2(2): 7.

\section{ISSN: $2380-6036$}

4. Sponseller P (2001) Orthopedic update in Rett Syndrome. Rett Gazette.

5. Ben Zeev Ghidoni B (2007) Rett syndrome. Child Adolesc Psychiatr Clin N Am 16: 723-743.

6. Guerrini R, Parrini E (2012) Epilepsy in Rett syndrome, and CDKL5- and FOXG1-gene-related encephalopathies. Epilepsia 53: 2067-2078.

7. Kirby RS, Lane JB, Childers J, Skinner SA, Annese F, et al. (2010) Longevity in Rett syndrome: analysis of the North American Database. J Pediatr 156: 135-138.

8. Kaufmann WE, Johnston MV, Blue ME (2005) MeCP2 expression and function during brain development: implications for Rett syndrome's pathogenesis and clinical evolution. Brain Dev 27 Suppl 1: S77-S87.

9. Cass H, Reilly S, Owen L, Wisbeach A, Weekes L, et al. (2003) Findings from a multidisciplinary clinical case series of females with Rett syndrome. Dev Med Child Neurol 45: 325-337.

10. Moore H, Leonard H, de Klerk N, Robertson I, Fyfe S, et al. (2005) Health service use in Rett syndrome. J Child Neurol 20: 42-50.

11. Guy J, Gan J, Selfridge J, Cobb S, Bird A (2007) Reversal of neurological defects in a mouse model of Rett syndrome. Science 315: 1143-1147.

12. Kondo M, Gray LJ, Pelka GJ, Christodoulou J, Tam PP, et al. (2008) Environmental enrichment ameliorates a motor coordination deficit in a mouse model of Rett syndrome--Mecp2 gene dosage effects and BDNF expression. Eur J Neurosci 27: 3342-3350.

13. Jugloff DG, Vandamme K, Logan R, Visanji NP, Brotchie JM, et al. (2008) Targeted delivery of an Mecp2 transgene to forebrain neurons improves the behavior of female Mecp2-deficient mice. Hum Mol Genet 17: 1386-1396.

14. Bird A (2010) Current state of Rett syndrome molecular genetics. 2nd European Conference on Rett syndrome.

15. Coenraads M (2010) Looking for a cure to Rett syndrome. New directions and developments in research. 2nd European Conference on Rett syndrome.

16. Lotan M, Schenker R, Wine J, Downs J (2010) The conductive environment enhances gross motor function of girls with Rett syndrome. A pilot study. Dev Neurorehabil 15: 19-25.

17. Lotan M, Downs J, Elefant C. A pilot study delivering physiotherapy support for Rett syndrome over long distances via Skype supervision. Yet, unpublished data.

18. Elefant C, Wigram T (2005) Learning ability in children with Rett syndrome. Brain Dev 27 Suppl 1: S97-S101.

19. Elefant C (2001) Speechless yet communicative: Revealing the person behind the disability of Rett syndrome through clinical research on songs in music therapy. In: Aldridge D, di Franco G, Ruud E, Wigram T (eds). Music therapy in Europe. Rome: ISMEZ.

20. Koppenhaver DA, Erickson KA, Skotko BG (2001) Supporting communication of girls with Rett syndrome and their mothers in storybook readings. Int $J$ Disabil Dev Educ 48: 395-410.

21. Koppenhaver DA, Erickson KA, Harris B, McLellan J, Skotko BG, et al. (2001) Storybook-based communication intervention for girls with Rett syndrome and their mothers. Disabil Rehabil 23: 149-159.

22. Demeter K (2000) Assessing the developmental level in Rett syndrome: an alternative approach? Eur Child Adolesc Psychiatry 9: 227-233.

23. Jacobsen K, Viken A, von Tetchner S (2001) Rett syndrome and ageing: a case study. Disabil Rehabil 23: 160-166.

24. Hetzroni O, Rubin C, Konkol O (2002) The use of assistive technology for symbol identification by children with Rett syndrome. J Intellect Dev Disabil 27: $57-71$

25. Lindberg B (2006) Understanding Rett Syndrome: A practice guide for parents, teachers and therapists. The University of Virginia, Toronto: Hognefe Huber Publishers, USA.

26. Kerr A (1992) Communication in Rett syndrome. London: Rett Syndrome Association, UK.
27. Sigafoos J, Woodyatt G, Tucker M, Roberts-Pennell D, Pittendreigh N (1999) Assessment of potential communicative acts in three individuals with Rett syndrome. J Dev Phys Disabil 12: 203-216.

28. Sigafoos J (2000) Communication development and aberrant behavior in children with developmental disabilities. Educ Train Ment Retard Dev Disabil 35: 168-176.

29. Sigafoos J, Woodyatt G, Keen D, Tait K, Tucker M, et al. (2000) Identifying potential communicative acts in children with developmental and physical disabilities. Commun Disord Q 21: 77-86

30. Wine J (2009) Resource for the development of a communication program for girls with Rett syndrome. Israel: Rett Syndrome Foundation, Israel.

31. Downs J, Bebbington A, Kaufmann WE, Leonard H (2010) Longitudinal hand function in Rett syndrome. J Child Neurol 26: 334-340.

32. Sullivan MW, Laverick DH, Lewis M (1995) Brief report: fostering environmental control in a young child with Rett syndrome: a case study. $J$ Autism Dev Disord 25: 215-221.

33. Pizzamiglio MR, Nasti M, Piccardi L, Zotti A, Vitturini C, et al. (2008) Sensorymotor rehabilitation in Rett syndrome: a case report. Focus Autism Other Dev Disabl 23: 49-62.

34. Hetzroni O, Rubin C (1998) AAC instruction for children with Rett syndrome using assistive technology. Proceedings of the ISAAC, Dublin, Ireland, pp. 98: 361.

35. Maciques Rodríguez E, Lotan M (2011) Rett syndrome: Hippotherapy intervention. In: M Lotan, J Merrick (eds). Rett syndrome: Therapeutic interventions. Disability studies series, New York: Science Publishers, pp. 247-278.

36. Lotan M, Isakov E, Merrick J (2004) Improving functional skills and physical fitness in children with Rett syndrome. J Intellect Disabil Res 48: 730-735.

37. Downs JA, Bebbington A, Jacoby P, Msall ME, Mcllroy O, et al. (2008) Gross motor profile in rett syndrome as determined by video analysis. Neuropediatrics 39: 205-210.

38. Lotan M, Gootman A (2012) Regaining walking ability in individuals with Rett syndome: a case study. Int J Health Intellect Disabil 11: 163-169.

39. Larsson G, Engerstrom IW (2001) Gross motor ability in Rett syndrome-the power of expectation, motivation and planning. Brain Dev 23 Suppl 1: S77-S81.

40. Lotan M, Elefant C (2006) Physiotherapy and music therapy for a girl with Rett syndrome-a dual treatment approach. Fysioterapeuten 13: 15-20.

41. Lotan M, Isakov E, Merrick J (2004) Improving functional skills and physical fitness in children with Rett syndrome. J Intell Disabil Res 48: 730-735.

42. McClure MK, Battaglia C, McClure RJ (1998) The relationship of cumulative motor asymmetries to scoliosis in Rett syndrome. Am J Occup Ther 52: 196204.

43. Rossin L (1997) Effectiveness of therapeutic and surgical intervention in the treatment of scoliosis in Rett syndrome. A seminar work. Pittsburgh, PA: Univ Duquesne, pp. 1-19.

44. Lotan M, Merrick J, Carmeli E (2005) Managing scoliosis in a young child with Rett Syndrome: a case study. Sci World J 5: 264-273.

45. Budden SS (1995) Management of Rett syndrome: a ten year experience. Neuropediatrics 26: 75-77.

46. Sade SP, Sinuani BZ, Lotan M (2010) The proprioceptive system as a source for fear of movement in individuals with Rett syndrome. A study with clinical implications. A poster presented at the Annual Israeli Physical Therapy Association conference. 17-18 May, Tel-Aviv, Israel.

47. Kantor E, Lotan M (2009) Successful sensory integration intervention for a child with RS. Israel J Health Intellect Disabil 2: 154-62.

48. Lotan M, Zysman L (2011) Rett syndrome: Digestive system and nutritional considerations. In: Lotan M, Merrick J (eds.). Rett syndrome: Therapeutic interventions. Series: Disability Studies, Nova Science Publishers, New York 
Citation: Nissanholtz-Gannot R, Zigdon A, Lotan M. The Time is Now: The Need for an Intensive, Appropriate Individual Intervention for Individuals with Rett Syndrome. J Syndromes. 2015;2(2): 7.

ISSN: $2380-6036$

pp. $119-136$.

49. Motil KJ, Schultz R, Brown B, Glaze DG, Percy AK (1994) Altered energy balance may account for growth failure in Rett syndrome. J Child Neurol 9: 315-319

50. Motil K (1996) Nutrition and weight management. Presentation, IRSA 12th Ann Conf, Boston, MA, Tape 622-611.

51. Prior C, Nunes A, Rios M, Sequeiros J, Maciel P, et al. (2010) Nutrition and gastrointestinal disorders in Rett syndrome: Importance of early intervention. An Pediatr (Barc) 72: 191-198.

52. Rice M (1989) Nutrition care guidelines for Rett syndrome. La Jolla, CA Neurometab Clinic, Department of Pediatrics, University of California.

53. Rogers A, Furler BL, Brinks S, Darrah J (2008) A systematic review of the effectiveness of aerobic exercise interventions for children with cerebral palsy: an AACPDM evidence report. Dev Med Child Neurol 50: 808-814.

54. Rendtorff JD (2002) Basic ethical principles in European bioethics and biolaw: automnomy, dignity, integrity and vulnerability--towards a foundation of bioethics and biolaw. Med Health Care Philos 5: 235-244.

55. Glendon MA (2001) A world made new: Eleanor Roosevelt and the Universal Declaration of Human Rights. New York: Random House.

56. Rao N (2012) American dignity and healthcare reform. Harv J Law Public Policy 35: 171-184

57. Tushnet MV (2001) Thurgood Marshall: His speeches, writings, arguments, opinions and reminiscences. Library of Black America, Lawrence Hill Books, New York.

58. Williams A, Cookson R (2000) Equity in Health. In: Culyer AJ, Newhouse JP (eds.). Handbook of Health Economics. Elsevier North-Holland, New York, pp. 1864-1910.
59. Marmot Review Commission (2010) Fair society, healthy lives: The Marmot Review. Strategic Review of Health Inequalities in England Post-2010. London: Marmot Review.

60. Beauchamp TL, Childress JF (1994) Principles of biomedical ethics (4th edn). New York: Oxford University Press.

61. Schor E (2008) US environmental agency lowers value of a human life. The Guardian UK 2008.

62. Beeri E (2012) Medicine meets economy: the cost effectiveness of pediatric rehabilitation. Alyn 1st international pediatric conference.

63. Eddy DM (1990) Clinical decision making: from theory to practice. What do we do about costs? JAMA 264: 1161-1170.

64. Weinstein MC, Stason WB (1977) Foundations of cost-effectiveness analysis for health and medical practices. N Engl J Med 296: 716-721.

65. Neumann PJ, Johannesson M (1994) From principle to public policy: using cost-effectiveness analysis. Health Aff (Millwood) 13: 206-214.

66. Tilford JM, Aitken ME, Goodman AC, Fiser DH, Killingsworth JB, et al. (2007) Child health-related quality of life following neurocritical care for traumatic brain injury: an analysis of preference-weighted outcomes. Neurocrit Care 7: 64-75.

67. Lotan M (2015) Walking in Rett syndrome. An oral presentation at the $30^{\text {th }}$ Anniversary Family Weekend 9-1 $11^{\text {th }}$ October 2015, Northampton, UK.

68. Kerr AM (1994) The future for rett syndrome girls. International Rett Syndrome Association Newsletter.

69. Guralnick MJ (2005) Early intervention for children with intellectual isabilities: current knowledge and future prospects. J Appl Res Intellect Disabil 18: 313 324. 